LIIIANE ORTIZ TEIXERA ${ }^{1}$

Suélen CAVAlheiro Amaral ${ }^{2}$

FABIANA FINGER-JARDIM 1

VANusa POUSADA Da Hora ${ }^{3}$

Carla Vitola Gonçalves ${ }^{4}$

Marcelo Alves Soares ${ }^{5}$

Ana Maria BarRal de Martinez ${ }^{3}$

Artigo Original

Palavras-chave

Genótipo

Biologia molecular

Transmissão vertical de doença infecciosa

Doenças sexualmente transmissíveis

Keywords

Genotype

Molecular biology

Infectious disease transmission, vertical Sexually transmitted diseases

\title{
Frequência do Papilomavírus Humano na placenta, no colostro e no sangue do cordão umbilical
}

\author{
Frequency of Human Papillomavirus in the placenta, \\ in the colostrum and in the umbilical cord blood
}

\section{Resumo}

OBJETIVO: Determinar a frequência do Papilomavírus Humano (HPV) na placenta, no colostro e no sangue do cordão umbilical de parturientes e seus neonatos atendidos no Ambulatório de Ginecologia e Obstetrícia do Hospital Universitário de Rio Grande (RS), Brasil. MÉTODOS: Foram coletadas biópsias de 150 placentas do lado materno, 150 do lado fetal, 138 amostras do sangue do cordão umbilical e 118 amostras de colostro. As biópsias de placenta foram coletadas da porção central e periférica. O DNA foi extraído segundo protocolo do fabricante e conforme referência encontrada na literatura. O HPV foi detectado pela técnica da reação em cadeia da polimerase aninhada (PCR-Nested) com os primers MYO9/ 11 e GP5/GP6. A genotipagem foi por sequenciamento direto. As participantes responderam a um questionário autoaplicado com dados demográficos e clínicos, a fim de caracterizar a amostra. RESULTADOS: HPV foi detectado em 4\% (6/150) do lado materno das placentas, 3,3\% (5/150) do lado fetal; 2,2\% (3/138) no sangue do cordão e 0,8\% (1/1 1 8) no colostro. A taxa de transmissão vertical foi de 50\%. $\bigcirc$ genótipo de baixo risco oncogênico encontrado foi o HPV-6 (60\%) e de alto risco, os HPV-16 e HPV-1 8 (20\% cada). CONCLUSÕES: Esses resultados sugerem que o HPV pode infectar a placenta, o colostro e o sangue do cordão umbilical.

\section{Abstract}

PURPOSE: To determine the frequency of Human Papillomavirus (HPV) in the placenta, in the colostrum and in the umbilical cord blood of parturient women and their newborns assisted at the Clinic of Gynecology and Obstetrics of the University Hospital of Rio Grande (RS), Brazil. METHODS: Biopsies were collected from 150 placentas on the maternal side, 150 on the fetal side, 138 samples of umbilical cord blood and 118 of the colostrum. The placenta biopsies were collected from the central and peripheral portions. DNA was extracted according to the manufacturer's protocol and to a reference found in the literature. HPV was detected by the nested polymerase chain reaction (PCR-Nested) using primers MYO9/1 1 and GP5/GP6. Genotyping was performed by direct sequencing. The participants responded to a self-applied questionnaire with demographic and clinical data, in order to characterize the sample. RESULTS: HPV was detected in $4 \%(6 / 150)$ of cases on the mother's side of the placentas, in $3.3 \%(5 / 150)$ on the fetal side, in $2.2 \%(3 / 138)$ in umbilical cord blood and in $0.84 \%(1 / 118)$ in colostrum samples. The vertical transmission rate was $50 \%$. HPV-6 was the low-risk genotype found $(60 \%)$ and the high-risk genotypes were HPV- 16 and HPV-1 8 (20\% each). CONCLUSIONS: These results suggest that HPV can infect the placenta, the colostrum and the umbilical cord blood.

Correspondência

Carla Vitola Goncalves Área acadêmica da Saúde, Universidade Federal do Rio Grande (FURG) Laboratório de Biologia Molecular, Foculdade de Medicina Rua General Osório, $s / n-$ Centro CEP: $96200-190$

Rio Grande (RS), Brasil

Recebido

$03 / 02 / 2015$

Aceito com modificacộes $24 / 03 / 2015$
Laboratório de Biologia Molecular, Hospital Universitário, Universidade Federal do Rio Grande - FURG - Rio Grande (RS), Brasil. IPrograma de Pós-graduação (Doutorado) em Ciências da Saúde, Universidade Federal do Rio Grande - FURG - Rio Grande (RS), Brasil. 2Programa de Pós-graduação (Mestrado) em Ciências da Saúde, Universidade Federal do Rio Grande - FURG - Rio Grande (RS), Brasil. 3Faculdade de Medicina, Universidade Federal do Rio Grande - FURG - Rio Grande (RS), Brasil. 4Faculdade de Medicina, Universidade Federal do Rio Grande - FURG - Rio Grande (RS), Brasil.

${ }^{5}$ Instituto Nacional de Câncer - INCA - Rio de Janeiro (RJ), Brasil.

Conflito de interesses: não há. 


\section{Introdução}

A infecção pelo Papilomavírus Humano (HPV) é a doença sexualmente transmissível viral mais frequente no mundo, sendo que, para o Brasil, são estimados 685.400 novos casos de HPV anualmente ${ }^{1}$. Esse vírus mucosotrópico infecta células epiteliais e está relacionado ao desenvolvimento de verrugas genitais, do câncer de colo do útero, do câncer de cabeça e pescoço, do câncer anal e da papilomatose respiratória recorrente (PRR) ${ }^{2,3}$. Os HPVs são classificados em baixo risco oncogênico, associados com as verrugas genitais e a PRR, ou em alto risco oncogênico, associados com os cânceres ${ }^{4}$.

Além da transmissão sexual, o HPV pode ser transmitido verticalmente. Essa transmissão pode ser pela via ascendente de contaminação, pela via hematogênica através da placenta ou durante a passagem do neonato pelo canal do parto ${ }^{5}$. A PRR é a doença resultante da transmissão vertical dos genótipos de baixo risco HPV-6 e HPV-11 e é caracterizada pelo crescimento de múltiplas lesões exofíticas na laringe, podendo ocorrer ao longo de todo aparelho respiratório ${ }^{6,7}$.

Estudos relataram que o HPV pode infectar a placenta humana ${ }^{8-11}$, o sangue do cordão umbilical ${ }^{10,11}$ e o colostro ou leite materno ${ }^{12,13}$. No entanto, ainda não há um consenso na literatura sobre a transmissão materno-infantil do $\mathrm{HPV}^{10}$. Dessa forma, estudos sobre esse tema são essenciais para elucidar a ocorrência e a história natural da transmissão vertical do HPV, a fim de que medidas preventivas sejam otimizadas. Dentro desse contexto, o objetivo do presente estudo foi determinar a frequência do HPV na placenta, no colostro e no sangue do cordão umbilical.

\section{Métodos}

Este estudo transversal descritivo exploratório foi realizado no Hospital Universitário da cidade do Rio Grande - Hospital Dr. Miguel Riet Corrêa Jr. da Universidade Federal do Rio Grande (FURG) entre os meses de agosto de 2011 e junho de 2012. A amostragem foi de conveniência, sendo selecionada de forma sequencial ao atendimento. Foram excluídas as mulheres que apresentaram deficiência mental. As gestações múltiplas com placentas isoladas foram analisadas independentemente.

Imediatamente após o parto, $4 \mathrm{~mL}$ do sangue arterial do cordão umbilical foram coletados e armazenados em tubos com EDTA. As biópsias da porção central e periférica da placenta, tanto no lado materno quanto no lado fetal, foram coletadas e armazenadas em tubos contendo solução tampão T.E. (Tris-HCl $10 \mathrm{mM} \mathrm{pH} \mathrm{8,0;} \mathrm{EDTA}$ $1 \mathrm{mM})^{10}$. O colostro foi coletado entre 24 e 48 horas após o parto e foi acondicionado em tubos cônicos estéreis. Com a finalidade de evitar contaminações, as amostras de colostro foram transferidas para tubos de microcentrífuga, sendo posteriormente centrifugadas a $2.000 \mathrm{rpm}$ durante 10 minutos. O soro do colostro e a gordura foram removidos e o sedimento foi ressuspendido com a solução tampão T.E. ${ }^{14}$.

Todas as amostras foram armazenadas a $-20^{\circ} \mathrm{C}$ até a extração do DNA, que foi realizada a partir do kit comercial PureLink ${ }^{\circledR}$ Genomic DNA Mini Kit ${ }^{15}$. A extração do sangue do cordão umbilical e do colostro foi realizada segundo o protocolo de extração de células sanguíneas ${ }^{15}$. O DNA da biópsia da placenta foi extraído segundo protocolo do fabricante com modificação previamente descrita na literatura ${ }^{16}$. Para a digestão proteica das biópsias de placenta, as amostras foram submetidas a $55^{\circ} \mathrm{C}$ durante 12 horas em vez de 10 minutos a $55^{\circ} \mathrm{C}$, como consta no protocolo do kit. O DNA proveniente das extrações foi armazenado a $-20^{\circ} \mathrm{C}^{15}$.

Para garantir a viabilidade do DNA, foi amplificado um fragmento de $222 \mathrm{pb}$ para o receptor de quimiocina humano CCR2 pela técnica da reação em cadeia da polimerase (PCR), utilizando os primers senso 5'TTGTGGGCAACATGATGG3' e anti senso 5'TGAAGAAGATTCCGCCAAAA3'17. $\mathrm{O}$ mix teve o volume final de $50 \mu \mathrm{L}$, sendo constituído por 1,25 U da enzima Taq DNA polimerase; primers na concentração de $25 \mathrm{pmol} / \mu \mathrm{L}$ cada; $0,5 \mathrm{mM}$ de $\mathrm{MgCl}_{2}$; 0,2 mMol de DNTP; tampão da enzima taq 1x e $\mathrm{H}_{2} \mathrm{O}$ MiliQ. A PCR foi realizada no termociclador PTC150 MinicyclerTM termocycler (MJ Research Inc., Waltham, MA, USA). A ciclagem foi: $95^{\circ} \mathrm{C}$ por 10 minutos, seguido de 38 ciclos subsequentes de $95^{\circ} \mathrm{C}$ por 30 segundos para desnaturação, $57^{\circ} \mathrm{C}$ por 30 segundos para anelamento e $72^{\circ} \mathrm{C}$ por 1 minuto para extensão. A extensão final foi de 10 minutos a $72^{\circ} \mathrm{C}^{17}$. Para controle positivo, foi utilizada uma amostra de sangue total com DNA extraído segundo as orientações do fabricante.

Para determinação do Papilomavírus, foi realizada uma PCR aninhada (Nested). O primeiro "round" foi realizado com os primers externos MY09/ MY1: 5'CGTCCMAARGGAWACTGATC3' / 5'GCMCAGGGWCATAAYAATGG3'18, que geram um produto de $450 \mathrm{pb}$ da região L1 do capsídeo viral. No segundo "round", foram utilizados os primers internos GP5/6: 5'TTTGTTACTCTGGTAGATAC3'/5'GAAA AATAAACTGTAAATCA3"18, que amplificam $150 \mathrm{pb}$ também da região L1. As duas PCRs foram realizadas com um volume final de $50 \mu \mathrm{L}$, sendo constituído por 2,5 U da enzima Taq DNA polimerase; primers na concentração de $25 \mathrm{pmol} / \mu \mathrm{L}$ cada; 3,0 mM de $\mathrm{MgCl}_{2}$; 0,20 mMol de DNTPs; tampão da enzima taq $1 \mathrm{x}, 50 \mathrm{mM}$ de $\mathrm{KCl}$, e $\mathrm{H}_{2} \mathrm{O}$ Mili-Q. No primeiro round, foram utilizados $5 \mu \mathrm{L}$ de DNA e, no segundo, $5 \mu \mathrm{L}$ do produto da PCR MY. As condições no termociclador para o primeiro round foram constituídas pelas seguintes etapas: $94^{\circ} \mathrm{C}$ por 5 minutos, 
para desnaturação inicial, seguindo de 40 ciclos subsequentes de $94^{\circ} \mathrm{C}$ por 35 segundos para desnaturação, $55^{\circ} \mathrm{C}$ por 45 segundos para anelamento e $72^{\circ} \mathrm{C}$ por 45 segundos para amplificação, seguidos de $72^{\circ} \mathrm{C}$ por 5 minutos para extensão final ${ }^{18}$. A PCR foi realizada no termociclador MJ research. Como controle positivo da reação, foi usado um fragmento de $450 \mathrm{pb}$ correspondente ao DNA do HPV integrado às células SiHa. Para o controle negativo, foi realizada uma PCR com todos os reagentes, exceto o DNA.

Os resultados das extrações e das PCRs foram confirmados por eletroforese em gel de agarose $0,8 \%$ para extração do DNA; $1,0 \%$, para PCR MY09/11; 1,5\% para as PCRs do receptor CCR 2 e $2 \%$ para a PCR GP. Os fragmentos foram visualizados por fluorescência UV por um sistema de fotodocumentação EDAS Kodak após ter sido banhado em brometo de etídio $(10 \mathrm{mg} / \mathrm{mL})$, e o tamanho do fragmento gerado por PCR foi comparado com o marcador de peso molecular Leidwing Biotc ${ }^{\circledR}$ Ladder 100 pb Plus.

A determinação dos genótipos do HPV foi realizada por sequenciamento do produto de PCR na Divisão de Genética do Instituto Nacional de Câncer (INCA) do Brasil. Os produtos de PCR foram purificados pelo kit Illustra $^{\text {TM }}$ GFX ${ }^{\text {TM }}$ PCR DNA and Gel Band Purification (GE Health Care) conforme protocolo do fabricante ${ }^{19}$. Os produtos purificados foram sequenciados com o kit $\mathrm{ABI}$ Prism ${ }^{\circledR}$ BigDye $^{\mathrm{TM}}$ Terminator Cycle Sequencing Ready Reaction (AppliedBiosystems ${ }^{\circledR}$, Foster City, USA) conforme o protocolo do fabricante ${ }^{20}$. O sequenciador automático utilizado foi o ABI 3130XL (Life Technologies). Foram utilizados os programas: SeqMan (Lasergene 9, DNASTAR Inc., Madison, USA) e CLUSTAL W - BioEdit para editar as sequências de nucleotídeos. Para a confirmação e identificação do tipo do HPV, foi realizada a comparação das sequências nucleotídicas das amostras sequenciadas, submetendo-as ao Banco de Dados Mundial de Nucleotídeos - Gene Bank, utilizando o programa BLAST.

Todos os dados foram revisados, codificados e duplamente digitados no software EpiData ${ }^{\circledR 21}$. Os dados descritivos são apresentados no texto e em tabelas, na forma de frequência absoluta e relativa em percentual.

Este estudo foi aprovado pelo Comitê de Ética em Pesquisa na Área da Saúde (CEPAS) da FURG, número 54/2011. Participaram do estudo as mulheres que concordaram em assinar o Termo de Consentimento Livre e Esclarecido. Este estudo está de acordo com o Código de Ética da Associação Médica Mundial (Declaração de Helsinki) para experimentos envolvendo seres humanos.

\section{Resultados}

Concordaram em participar do estudo 153 mulheres. Houve cinco gestações gemelares, sendo dois monozigóticos e três dizigóticos com placentas independentes e isoladas. Essas placentas isoladas foram analisadas separadamente, totalizando 156 placentas. Em seis amostras, não foi possível extrair o DNA do lado materno e/ou fetal, sendo consideradas como perda. Assim, foram analisadas 150 placentas. Em relação ao sangue do cordão umbilical e o colostro, foram coletados 138 e 118 amostras, respectivamente.

A maioria das participantes se autodeclararam brancas $(61,2 \%)$, apresentavam um companheiro fixo $(71,3 \%)$, tinham mais de 24 anos $(50,4 \%)$, com mais de 9 anos de escolaridade $(53,6 \%)$ e não eram tabagistas $(85,3 \%)$. Em relação à renda, a maioria tinha entre 1 e 2 salários mínimos $(34,4 \%)$ e 93,6\% declararam não ter uma história prévia de infecção por uma DST (Tabela 1 ).

O DNA do HPV foi detectado em $4 \%$ (6/150) do lado materno das placentas, em 3,3\% (5/150) do lado fetal; em 2,2\% (3/138) do sangue do cordão e em 0,84\% $(1 / 118)$ das amostras de colostro. Não houve diferença no resultado negativo de placentas provenientes de gêmeos.

Das seis amostras de placenta positiva para o HPV, o vírus foi detectado em todas do lado materno e em cinco do lado fetal. Essas seis mães positivas transmitiram o HPV para o sangue do cordão de três neonatos, sendo a taxa de transmissão vertical de $50 \%$.

Tabela 1. Características demográficas e epidemiológicas das parturientes atendidas no Hospital Universitário de Rio Grande em 2011 e 2012

\begin{tabular}{|c|c|c|}
\hline \multirow{2}{*}{ Variáveis } & \multicolumn{2}{|c|}{ Característica } \\
\hline & $n$ & $\%$ \\
\hline \multicolumn{3}{|l|}{ Cor } \\
\hline Branca & 87 & 61,2 \\
\hline Não branca & 55 & 38,8 \\
\hline \multicolumn{3}{|l|}{ Condição civil } \\
\hline Com companheiro & 102 & 71,3 \\
\hline Sem companheiro & 41 & 28,7 \\
\hline \multicolumn{3}{|l|}{ Idade (anos) } \\
\hline$\geq 25$ & 72 & 49,6 \\
\hline$\leq 24$ & 73 & 50,4 \\
\hline \multicolumn{3}{|l|}{ Nível de escolaridade (anos) } \\
\hline$\geq 9$ & 74 & 53,6 \\
\hline$\leq 8$ & 64 & 46,4 \\
\hline \multicolumn{3}{|l|}{ Renda* } \\
\hline Mais de dois salários mínimos & 44 & 33,6 \\
\hline Entre um e dois salários mínimos & 45 & 34,4 \\
\hline Menos que um salário mínimo & 42 & 32,0 \\
\hline \multicolumn{3}{|l|}{ Tabagismo } \\
\hline Não & 122 & 85,3 \\
\hline Sim & 21 & 14,7 \\
\hline \multicolumn{3}{|l|}{ História prévia de DST } \\
\hline Não & 133 & 93,6 \\
\hline Sim & 9 & 6,4 \\
\hline
\end{tabular}

*Salário mínimo na época do estudo: R\$700,00. DST: doença sexualmente transmissível. 
Os genótipos encontrados foram: 60\% HPV-6 (3/5), 20\% HPV-16 (1/5), 20\% HPV-18 (1/5). Todas as amostras de uma paciente não foram determinadas devido à sobreposição de picos observadas no sequenciamento.

\section{Discussão}

As frequências do HPV na placenta e no sangue do cordão umbilical foram similares aos dados encontrados em estudos prévios ${ }^{9,10}$. Outros estudos encontraram frequências entre $0^{11}$ e $42 \%{ }^{8}$. É importante salientar que esse último estudo com uma frequência elevada de HPV na placenta foi realizado em mulheres com citopatológico sugestivo de HPV. Estudos realizados com a população em geral observaram frequências menores que $4,5 \% \%^{9-11}$. No presente estudo, foi pesquisado o HPV na placenta de mulheres da população em geral e o resultado do citopatológico não foi analisado em razão de as mulheres chegarem ao hospital apenas no momento do parto.

A transmissão do HPV através do aleitamento materno ainda não está estabelecida ${ }^{12-14}$. Apesar da hipótese de que essa transmissão pode não ocorrer porque o HPV não provoca viremia ${ }^{13}$, já foi observado que o HPV encontrado no leite materno pode estar viável e infectante ${ }^{22}$. Estudar novas formas de transmissão do HPV como pelo banco de leite e pelo transplante de células totipotentes do cordão umbilical é importante na elaboração de medidas que interrompam a cadeia de transmissão.

O HPV-6 foi o genótipo mais frequente neste estudo. Isso está de acordo com os dados da literatura que mostram que esse genótipo está relacionado com a transmissão vertical ${ }^{6,7}$. Os outros dois genótipos encontrados (HPV-16 e HPV-18) são descritos na literatura como os mais frequentes ${ }^{23,24}$. Nas amostras de placenta e do sangue do cordão umbilical provenientes de uma parturiente, a determinação do genótipo não foi possível devido à sobreposição dos picos das sequências, o que indica a infecção por múltiplos genótipos ${ }^{25}$. No entanto, como o objetivo do estudo foi determinar a frequência do HPV na placenta, no colostro e no sangue do cordão umbilical, este trabalho teve seu propósito alcançado com a metodologia utilizada.

Este estudo apresentou limitações. Os resultados não podem ser extrapolados para todas as mulheres grávidas e recém-nascidos porque este estudo utilizou uma amostragem de conveniência. Além disso, não foi possível coletar o sangue do cordão umbilical e o colostro de todas as 153 participantes devido às rotinas no centro obstétrico e às características dos pacientes e da placenta. O colostro não foi coletado em casos de natimortos, em pacientes HIV-1 positivos (devido ao procedimento para evitar a lactação nessas mulheres), no parto cesárea (em alguns casos, devido à baixa produção de colostro), quando os recém-nascidos estavam na unidade de terapia intensiva e quando a paciente se sentiu desconfortável durante a coleta. O sangue do cordão umbilical não foi coletado em natimortos (devido à má formação do cordão umbilical ou autólise do mesmo), em mulheres com fator Rh negativo (a coleta de sangue foi necessária para análise em laboratório), em casos com complicações no parto (o sangue foi drenado antes que pudesse ser coletado) e quando a placenta tinha uma coagulação rápida.

Este trabalho tem uma grande importância epidemiológica por ser o primeiro realizado na região. É possível sugerir que o HPV infecta a placenta e é capaz de ser transmitido para o sangue do cordão umbilical e para o colostro. A continuidade deste estudo é importante para aprofundar o conhecimento sobre a infecção do HPV na placenta, no colostro e no sangue do cordão umbilical ao longo do tempo, desde o pré-natal até o puerpério.

\section{Agradecimentos}

À Coordenação de Aperfeiçoamento de Pessoal de Nível Superior (CAPES) e à Universidade Federal do Rio Grande (FURG), pelo financiamento do estudo.

Aos integrantes do Projeto Placenta do Laboratório de Biologia Molecular da Faculdade de Medicina da FURG e aos funcionários do Centro Obstétrico do Hospital Universitário da FURG.

\section{Referências}

1. Brasil. Ministério da Saúde. Departamento de DST, AIDS e Hepatites Virais [Internet]. DST no Brasil. Brasília (DF): Ministério da Saúde; 2013 [citado 2015 Mar 2]. Disponível em: <http://www.aids. gov.br/pagina/dst-no-brasil>

2. Moura MR, Costa AC. [HPV prevalence of HIV positive women attended in the center of reference STD/AIDS]. Rev Enferm UFPI. 2014;3(2):33-41. Portuguese.

3. Leon ME, Shamekh R, Coppola D. Human papillomavirus-related squamous cell carcinoma of the anal canal with papillary features. World J Gastroenterol. 2015;21 (7):2210-3.
4. Dochez C, Bogers JJ, Verhelst R, Rees H. HPV vaccines to prevent cervical cancer and genital warts: an update. Vaccine. 2014;32(14):1595-601.

5. Jach R, Galarowicz B, Huras H, Pawlik D, Basta T, Streb J, et al. Vertical transmission of HPV in pregnancy. A prospective clinical study of HPV-positive pregnant women. Ginekol Pol. 2014;85(9):672-6.

6. Omland T, Lie KA, Akre H, Sandlie LE, Jebsen P, Sandvik L, et al. Recurrent respiratory papillomatosis: HPV genotypes and risk of high-grade laryngeal neoplasia. PloS One. 2014;9(6):e99114. 
7. Marsico M, Mehta V, Chastek B, Liaw KL, Derkay C. Estimating the incidence and prevalence of juvenile-onset recurrent respiratory papillomatosis in publicly and privately insured claims databases in the United States. Sex Transm Dis. 2014;41(5):300-5.

8. Uribarren-Berrueta $O$, Sánchez-Corona J, Montoya-Fuentes $H$, Trujillo-Hernández B, Vásquez C. Presence of HPV DNA in placenta and cervix of pregnant Mexican women. Arch Gynecol Obstet. 2012;285(1):55-60.

9. Hernandez PB, Garcés MV, Romea EM, Tejero PC, Benito R, Oros D. Lower genital tract infection by HPV: correlation with HPV-induced trophoblastic dysfunction in late preterm birth. Ultrasound Obstet Gynecol. 2014;44(Suppl 1):68.

10. Lee SM, Park JS, Norwitz ER, Koo JN, Oh IH, Park JW, et al. Risk of vertical transmission of human papillomavirus throughout pregnancy: a prospective study. Plos One. 2013;8(6):e66368.

11. Hahn HS, Kee MK, Kim HJ, Kim MY, Kang YS, Park JS, et al. Distribution of maternal and infant human papillomavirus: risk factors associated with vertical transmission. Eur J Obstet Gynecol Reprod Biol. 2013;169(2):202-6.

12. Mammas IN, Zaravinos A, Sourvinos G, Myriokefalitakis N, Theodoridou M, Spandidos DA. Can 'high-risk' human papillomaviruses (HPVs) be detected in human breast milk? Acta Paediatr. 2011;100(5):705-7.

13. Yoshida K, Furumoto $H$, Abe A, Kato T, Nishimura M, Kuwahara A, et al. The possibility of vertical transmission of human papillomavirus through maternal milk. J Obstet Gynecol. 2011 ; 31(6):503-6.

14. Glenn WK, Whitaker NJ, Lawson JS. High risk human papillomavirus and Epstein Barr virus in human breast milk. BMC Res Notes. 2012;5:477.

15. Purelink $®$ Genomic DNA Kits: for purification of genomic DNA [Internet]. Catalog Numbers K1820-01, K1820-02, K1821-04 [cited 2015 Mar 2]. Available from: <https://tools.lifetechnologies. $\mathrm{com} /$ content/sfs/manuals/purelink_genomic_man.pdf>

16. Finger-Jardim F, Teixeira LO, Oliveira GR, Barral MF, Hora VP, Gonçalves CV, et al. Herpes simplex virus: prevalence in placental tissue and incidence in neonatal cord blood samples. J Med Virol. 2014;86(3):519-24.
17. Chaouch L, Kalai M, Jbara BM, Darragi I, Chaouachi D, Hafsia $\mathrm{R}$, et al. Association of MCP1-2518A/G and CCR2-V64I polymorphisms and vasoocclusive crisis among sickle cell anemia Tunisian patients. Interdiscip J Microinflamm. 2014;1:104.

18. Venceslau EM, Bezerra MM, Lopes AC, Souza EV, Onofre AS, Melo $C M$, et al. HPV detection using primers MY09/MY1 1 and GP5+/ GP6+ in patients with cytologic and/or colposcopic changes. J Bras Patol Med Lab. 2014;50(4):280-5.

19. GE Healthcare [Internet]. Illustra GFX PCR DNA and Gel Band Purification Kit: for the purification and concentration of DNA from PCR mixtures, restriction enzyme digestions, solutions and agarose gel bands: product booklet. 2008 [cited 2015 Mar 2]. Available from: <https://www.gelifesciences.com/gehcls_images/ GELS/Related\%20Content/Files/1314774443672/ litdoc28951562AA_20110831111511.pdf>

20. $A B I$ PRISM® BigDye ${ }^{T M}$ Terminator v3.0 Ready Reaction Cycle Sequencing Kit: Protocol [Internet]. 2001 [cited 2015 Mar 2]. Available from: <http://www.calpoly.edu/ bio/ubl/protocols_files/ bigdye3.pdf>

21. Lauritsen JM, editor. EpiData Data Entry, Data Management and basic Statistical Analysis System [Internet]. Odense: EpiData Association; 2000-2008 [cited 2015 Mar 2]. Available from: <http://www.epidata.dk>

22. Donalisio M, Cagno V, Vallino M, Moro GE, Arslanoglu S, Tonetto $P$, et al. Inactivation of high-risk human papillomaviruses by Holder pasteurization: implications for donor human milk banking. J Perinat Med. 2014;42(1):1-8.

23. Bruno A, Serravalle K, Travassos AG, Lima BG. [Genotype distribution of human papillomavirus in women from the state of Bahia, Brazil]. Rev Bras Ginecol Obstet. 2014;36(9):416-22. Portuguese.

24. Tamegão-Lopes BP, Sousa-Júnior EC, Passetti F, Ferreira CG, de Mello WA, Silvestre RV. Prevalence of human papillomavirus infection and phylogenetic analysis of HPV-16 E6 variants among infected women from Northern Brazil. Infect Agent Cancer. 2014;9:25.

25. Entiauspe LG, Silveira M, Nunes EM, Basgalupp SP, Stauffert D, Dellagostin OA, et al. High incidence of oncogenic HPV genotypes found in women from Southern Brazil. Braz J Microbiol. 2014;45(2):689-94. 